\title{
VARIAÇÕES DO NÍVEL MÉDIO ANUAL DO MAR EM CASCAIS: CARACTERÍSTICAS E TENDÊNCIAS
}

\author{
António Amílcar Alves da Silva *, Elisabete Freire ** \& Gonçalo Crisóstomo *
}

Resumo

Abstract

* Instituto Geográfico Português (IGP), R. Artilharia Um 107, 1099-052 Lisboa. Tel.213819600.

** Faculdade de Arquitectura da Universidade Técnica de Lisboa (FAUL). Departamento de Ciências Sociais, Rua Sá Nogueira, Pólo Universitário, Alto da Ajuda, 1349-055 Lisboa.

\begin{abstract}
Quando se estudam as variações do nível do mar, nomeadamente, quando se trata de um fenómeno que é tido como um dos principais sintomas ou consequência de eventuais alterações climáticas em curso, tidas por graves e em geral atribuídas à acção antrópica, há que ter em consideração a qualidade e a quantidade dos dados que poderão servir para este tipo de análise. Os registos maregráficos de Cascais têm vindo a ser utilizados como referência para avaliar a variações do nível do mar (NM) em Portugal, por exemplo através da determinação do nível médio de referência, assim como do estabelecimento de projeç̧ões desse nível no futuro, por se tratar de uma das séries mais longas que existem e das que apresentam menos lacunas. Neste artigo, após uma abordagem prévia do conceito de nível do mar, efectua-se uma análise das variações inter-anuais do nível médio anual, obtido a partir desses registos, tendo por princípio que essa variação representa a acção conjugada de uma multiplicidade de factores condicionantes, onde o contributo de cada um não é contínuo no espaço e no tempo. Há ainda a considerar, para além das contingências naturais, as estruturais, que condicionam as medições dos valores das alturas de água e os processos estatísticos que atravessam até se obter o nível médio anual. Neste contexto, algumas questões foram exploradas, nomeadamente a de ser possível traduzir matematicamente o comportamento de um fenómeno tão complexo reflectido na distribuição de frequências e que possa permitir a elaboração de projecções da variação do nível médio do mar num futuro próximo. Aplicaram-se alguns métodos estatísticos e gráficos, numa tentativa de avaliar o comportamento e valores relativos e de estabelecer uma previsão das tendências de evolução do NM. Discutem-se ainda as limitações dos dados no sentido de impor alguma cautela na avaliação das oscilações registadas e, sobretudo, na projecção de níveis futuros. O objectivo último é que estas assentem em dados objectivos e não conduzam a resultados pré concebidos.
\end{abstract}

Palavras - chave: nível médio do mar, factores de variação, nível de referência, variações e tendências do NM.

\begin{abstract}
Changes in annual mean sea level in Cascais: characteristics and trends: sea level change is considered to be one of the main symptoms or consequences of climate changes, and it has been considered quite serious and, generally, taken as the result of human actions upon the environment., Thus, it is even more relevant to take into consideration the quality and quantity of data that can be used in this evaluation. Because it is the longest and most complete data collected in Portugal, the use of tide gauge records from Cascais has been used as a reference to evaluate sea level in the country, especially to calculate the reference sea level. In this paper, after the discussion of the concept of sea level and the factors that contribute to its complexity, we make an evaluation of its annual fluctuations, based on the fact that this is the result of multiple limitation factors where each contribution is not continuous on space and time. It has to be taken into account that apart the natural constraints there are also some structural ones which restraints the measurements of the sea heights but also the statistical approach that is needed to be undertaken in order to get the annual mean sea level. In this context, some questions have arisen, namely, if it would be possible to define mathematically the behaviour of a complex event that can both reflect its frequency distribution and allow the prediction of the sea level change in the nearest future. Some graphical and statistical tools were applied as an attempt to evaluate the performance of relative values and to predict the tendencies of sea level evolution. We also discuss the data quality and the caution that must be used on the assessment of recorded fluctuations, mostly when making predictions for the future sea levels. The ultimate aim is that these conclusions will be used to assess the factual data and that preconception will be avoided.
\end{abstract}

Key - words: mean sea level, variation factors, reference level, sea level variations, sea level trends. 


\section{INTRODUÇÃo E OBJECTIVOS}

As notícias relativas à eventual subida do nível do mar (SNM), têm surgido nos meios de comunicação social numa perspectiva catastrofista, muitas vezes suportada por entidades e pessoas ligadas ao meio científico.

O presente artigo pretende abordar esta questão, numa perspectiva objectiva, isto é, apoiada na análise de dados registados, nomeadamente os obtidos a partir do marégrafo de Cascais, cuja longevidade da série de registos ${ }^{1}$ permite esboçar algumas ideias sobre o tema. Por outro lado, quando se fala em nível médio do mar ou simplesmente, nível do mar, há que ter consciência do que isso significa e das implicações que tem. Também há que considerar as contingências (naturais e estruturais) que condicionam as medições dos valores das alturas de água e os procedimentos que sofrem até se obter o nível médio anual que vai ser objecto de análise neste artigo.

Neste contexto, será efectuada a análise do NM anual a partir dos registos disponíveis do marégrafo situado em Cascais. Com estes dados serão efectuados alguns exercícios de análise estatística no sentido de identificar variações temporais do nível do mar e suas tendências evolutivas.

\section{Pressupostos e Metodologia}

\subsection{Definição de Nível Médio do Mar}

O conceito de nível médio do mar não é uma referência objectiva, não se mede directamente. É um conceito ligado a uma escala temporal (mês, ano, etc.) que se traduz pela altura média da água do mar relativamente a um determinado ponto de referência da rede geodésica e calculado com base na variação de fenómenos periódicos de origem astronómica, nomeadamente marés, durante um longo período de tempo. Em Portugal, o nível médio adoptado, foi determinado com base em 56 anos de dados registados em Cascais e materializado através de marcas de nivelamento. $\mathrm{O}$ nível médio cartográfico é medido em função de uma marca de nivelamento de alta precisão, situada junto à boca do poço do marégrafo de Cascais, designada por B1 - marca de contacto do marégrafo. O zero cartográfico adoptado desde 1938 por Helmert, fica a $4,308 \mathrm{~m}$ na vertical abaixo desta marca de nivelamento e corresponde ao nível médio anual que resultou da média de observações registadas entre 1882 e 1938.

Posteriormente, em 1950, recalibrou-se esta marca, mas a referência oficial continua a ser a de
1938. Por sua vez, o zero hidrográfico fica $2,08 \mathrm{~m}$ abaixo do nível médio adoptado, isto é $6,388 \mathrm{~m}$ abaixo da marca B1 (Fig. 1).

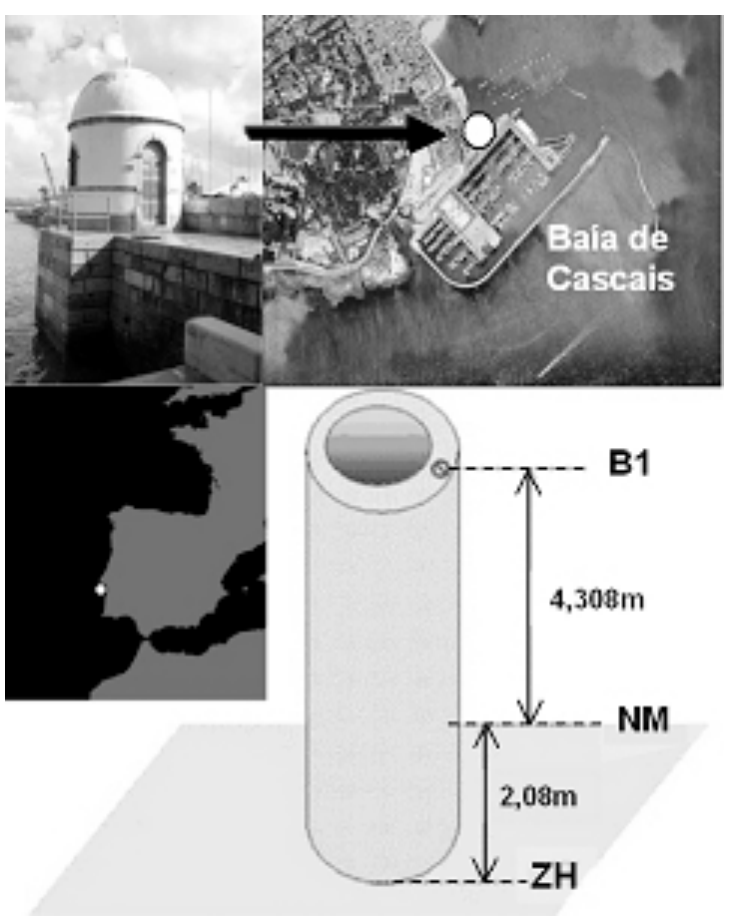

Fig. 1 - Marégrafo de Cascais e medição do nível médio do mar. Localização do marégrafo e esboço do poço e respectivas marcas de referência. B1-Marca de nivelamento que serve de referência ao NM (nível médio adoptado; designado nível médio cartográfico ou zero cartográfico); ZH-Zero hidrográfico.

Fig. 1 - Tide gauge of Cascais and measurement of the mean sea level. Tide gauge outline and location of the well. (Fonte das imagens/ source of images:

http://against.org/geocaching/wtiicache/maregrafo.jp; http://maps.google.com/).

Em função da escala temporal, o nível médio pode ser, designadamente, diário, mensal ou anual, não se devendo considerar os fenómenos que provoquem variações de período inferior à escala escolhida. Por exemplo, considerando o nível médio mensal eliminam-se as interferências devidas a marés e ondulação. Considerando-se o NM anual eliminam-se as oscilações provocadas pela desigual distribuição dos centros de pressão ao longo do ano. Há assim um processo de filtragem do registo.

No presente artigo, aborda-se o NM anual, cujo processo de cálculo passa actualmente pelo programa TASK (Tidal Analysis Software Kit) ${ }^{2}$, que é o suporte lógico utilizado pelo Permanent Service for Mean Sea Level, entidade internacional 
que calcula e valida os registos do marégrafo de Cascais ${ }^{3}$.

Apesar de ser um registo centenário, não se pode deixar de questionar a sua consistência em termos da validade dos seus dados, uma vez que ao longo do período de medição, houve mudanças de critérios de medição e análise, destacando-se o facto dos primeiros registos se referiam apenas às alturas de água na preia-mar e na baixa-mar, passando posteriormente a efectuar-se registos horários ${ }^{4}$. De algum modo, houve uma alteração no processo de obtenção do NM anual. Mas foi em 1938 que, com base nos valores médios registados até à data, se adoptou o NM actual.

Possivelmente por volta do início dos anos 50 (1950?), a marca altimétrica de referência do NM foi recalibrada, embora o NM adoptado se tenha mantido 5 .

Um dos factores que podem influenciar decisivamente os registos do NM, são os movimentos tectónicos. No entanto, o Instituto Geográfico Português (IGP), entidade responsável pelo marégrafo de Cascais e pela definição do datum altimétrico em Portugal, tem efectuado no local nivelamentos de precisão que atestam a respectiva imobilidade ao longo dos anos, não havendo por isso, lugar à necessidade de qualquer calibração. A inexistência de outros marégrafos na costa portuguesa com séries tão longas e consistentes como a de Cascais, impede de certo modo a validação dos dados (Fig. 2). Utilizaram-se também os dados do marégrafo de Lagos, que é a segunda série mais longa disponível, para efectuar algumas comparações quando há coincidência temporal da informação.

De acordo com estas contingências, a análise dos dados relativos ao registo anual do NM em Cascais, será baseado nas variações inter-anuais ocorridas em relação ao NM adoptado, que será o zero de referência ${ }^{6}$. Deste modo, cada valor do gráfico corresponde à diferença entre o valor do NM anual calculado e o zero.

Neste registo, existem ainda algumas lacunas relativas a anos em que houve problemas de aquisição de dados (1911-12; 1916 e 2002). Estes não serão considerados na análise de tendências.

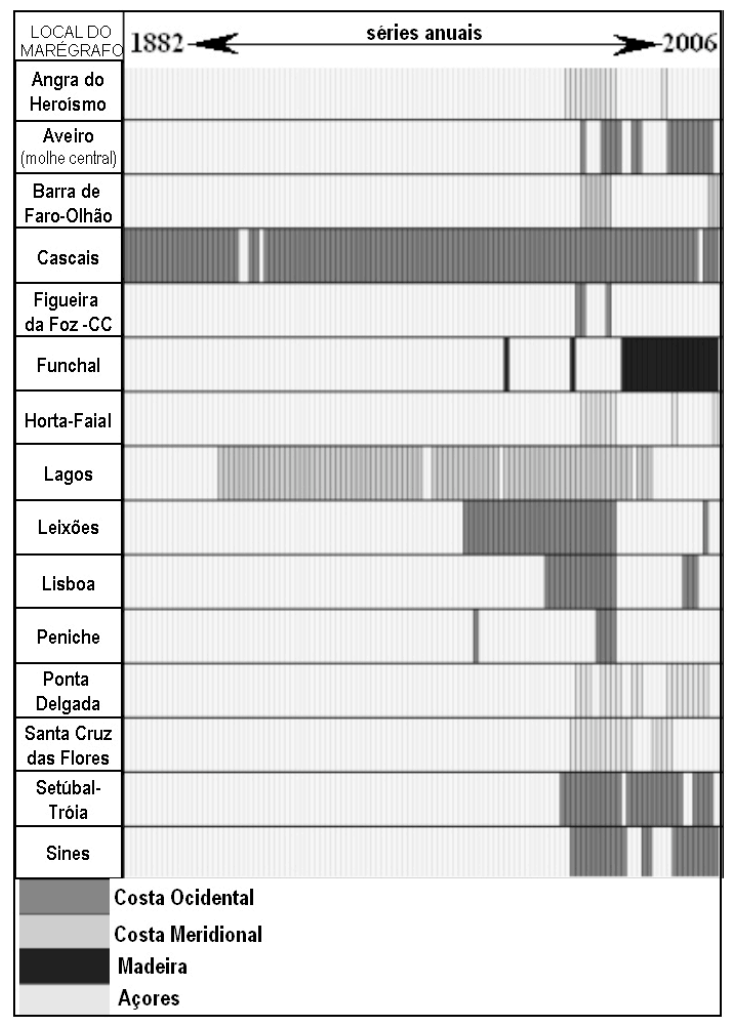

Fig. 2 - Séries temporais de registos maregráficos que existem em Portugal, entre 1882 e 2006.

Fig. 2 - Tide gauge time series of records that exist in Portugal, between 1882 and 2006.

Apesar da existência de algumas inconsistências e modificações dos critérios de medida ou ajustamentos que, de certo modo, diminuem a qualidade dos registos, esta é uma das séries mais longas que se conhecem em termos de dados obtidos de forma directa. Ainda que o NM anual seja um valor relativo (é uma média filtrada de valores médios mensais, que por sua vez derivam do cálculo de valores diários), tem como fonte um registo directo e real das oscilações sucessivas do nível do mar.

3 Actualmente, existe um novo marégrafo em Cascais, de tipo digital, que entrou em funcionamento em 2003, mas o antigo continua activo. O IH (Instituto Hidrográfico), actualmente, já possui meios para efectuar o cálculo dos valores do NM.

4 Não se conseguiu saber exactamente quando é que se passaram a efectuar registos horários, embora se pense que tenha sido após 1938.

5 Não foi possível confirmar o facto de poderem existir valores do NM anual calculados a partir de séries com falhas de dados mensais. Actualmente, dá-se como perdido um ano em que tenha havido mais de dois meses de lacunas. É pois possível que alguns valores padeçam desse defeito.

6 O valor do actual NM, segundo Dias (in TAVARES, et al., 2004) estará cerca de $20 \mathrm{~cm}$ acima do NM adoptado. Deste modo, o zero cartográfico está desfasado da realidade. 


\subsection{Factores de variação do nível do mar}

Apesar de serem sobejamente conhecidos, os factores de variação do nível do mar são muitas vezes omitidos em análises das variações do NM, nomeadamente se o objectivo for o de provar a correlação entre um eventual aquecimento global e a subida eustática. Existe uma multiplicidade de factores que actuam sobre o NM e, em geral, fazemse sentir de um modo descontínuo no espaço e no tempo, com maior ou menor interligação, ou com maior ou menor intensidade; de tal modo que, com as limitações que existem em termos de dados registados ou do conhecimento de todos os fenómenos e das relações que dinamizam esses factores, se prevê que se torne transcendente a concepção de um modelo capaz de prever variações do nível do mar. Neste artigo, considera-se que o registo observado é o reflexo dessa complexidade de fenómenos, dos quais apenas alguns, cíclicos, como as marés, são devidamente compreendidos e quantificados. Mas não são as marés que determinam as variações inter-anuais que se verificam nem as tendências que se podem desenhar. De acordo com Mörner (2005b), os modelos de previsão global devem ser questionados como ferramentas para compreender as variações dos NM locais e regionais. Globalmente, os factores conhecidos, são em geral pouco previsíveis e muito menos quantificáveis em termos prospectivos. Dos factores eustáticos, apenas se pode inferir uma relação com o ciclo das manchas solares, ainda assim de forma indirecta, que podem provocar fenómenos termo-eustáticos, com aumento ou retracção do volume dos oceanos por causa das variações da sua temperatura que, por sua vez, está também condicionada pela temperatura da atmosfera com a qual o oceano tem uma relação interactiva controladora do sistema climático. Todavia, o alcance destes fenómenos só teria um impacto global visível caso o balanço térmico seja definitivamente reajustado e desencadeie um reajustamento em termos do equilíbrio dinâmico do sistema climático. Os fenómenos glácio-eustáticos, dependentes da temperatura e da velocidade de fusão ou formação de gelo, têm uma inércia muito grande e é difícil quantificar o valor da oscilação do nível do mar correspondente a determinado volume de gelo fundido ou neoformado.

Por este motivo, também não é fácil definir com precisão quanto tempo durarão os movimentos isostáticos derivados do glacio-eustatismo. Recorde-se, que ainda hoje os territórios do norte da Europa, nomeadamente a Escandinávia, emergem devido à compensação isostática pós-glaciária, que poderá ter-se iniciado há cerca de 18 mil anos
(PASKOFF, 1985). No que diz respeito aos movimentos tectónicos, estes são quase imprevisíveis em termos de intensidade, velocidade e escala de abrangência espacial.

Já em relação ao relevo geoidal como factor de variação do nível do mar, com a utilização de satélites de precisão ${ }^{7}$, consegue-se actualmente ter uma noção dos desníveis existentes entre diferentes regiões do globo. Esses desníveis podem actualmente atingir um máximo de $3,4 \mathrm{~m}$ (CHAMBERS, 2006) sendo condicionados por diversos factores como sejam a pressão atmosférica, temperatura e densidade da água do mar (correntes térmicas e salinas), a batimetria (forma dos fundos oceânicos), ou as anomalias gravimétricas.

Conforme sugerem os relatórios do Painel Internacional para as Alterações Climáticas da Organização das Nações Unidas (IPCC, 2001), a existir um aumento generalizado da temperatura troposférica, com origem antrópica, considerando uma escala temporal abrangente, é lícito esperar que ocorra uma subida eustática generalizada do NM que lhe corresponda, ou um agravamento da tendência ascendente que se verifica desde o final do Würm até aos nossos dias. Mas essa correspondência não foi ainda claramente provada cientificamente e, em Portugal, uma análise deste fenómeno deverá ser, numa primeira fase, descontextualizada do global, de modo a que sejam considerados em primeiro lugar os factores regionais. Destes, há alguns conhecidos, passíveis de influenciar o nível do mar, como fenómenos neotectónicos (CABRAL, 1993) na costa ocidental e meridional do continente como, por exemplo, os que decorrem da aproximação das placas Africana e da micro-placa Ibérica, ou ainda fenómenos regionais/locais de subsidência ou levantamento tectónico, que alteram o nível relativo do mar. Recentemente, o caso do tsunami no Índico gerado por um mega-sismo na zona de contacto entre as placas Eurasiática e Australiana, junto a Sumatra, veio mostrar o potencial modificador que os fenómenos tectónicos têm em alterações súbitas do NM local. Em Portugal, há que considerar esta possibilidade, dados os antecedentes históricos neste âmbito. PEREIRA et al. (2006) referem e identificam diversos indícios de neo-tectónica em Portugal. Mas, este tipo de fenómenos, devem enquadrar-se numa escala temporal na ordem dos milhares de anos, pois o seu efeito global não é evidente à escala da vida de um ser humano. No âmbito dos factores resultantes da interacção oceano-atmosfera, o upwelling estival é um fenómeno anual recorrente que pode induzir variações no NM anual, para além das que são

\footnotetext{
7 Nomeadamente o TOPEX-Podeidon.
} 
determinadas pela alternância de altas e baixas pressões ao longo do ano e da eventual influência de modos canónicos globais relacionados com o clima, como o El-Niño (ENSO) ou a Oscilação Norte Atlântica (NAO) cuja influência se fará sentir com um certo desfasamento temporal entre a causa e o efeito.

Relativamente a fenómenos periódicos relacionados com factores atmosféricos e oceanográficos como as variações de pressão, marés equinociais, ondas de tempestade ou efeitos do vento sobre o mar, entre outros, não deve haver preocupação quando se estuda o NM anual, pois as anomalias relacionadas com estes factores são, em geral, localizadas no tempo, não tendo por isso grande influência no valor do NM anual. Já a influência periódica das marés correspondentes aos ciclos nodais de 18 anos, devem ser consideradas.

Todavia, quando os fenómenos anómalos são prolongados ou muito acentuados, então é possível que se possam reflectir naquele valor. Por outro lado, a inércia de alguns fenómenos pode só reflectir-se passado algum tempo e de forma nem sempre perceptível, sendo por isso difícil estabelecer relações concretas.

O mesmo não se pode dizer relativamente a tendências de longa duração na dinâmica do litoral (MÖRNER, 2005a), nomeadamente as induzidas pelas alterações do ciclo erosão-transportesedimentação no litoral, onde a actividade antrópica ao nível da alteração da dinâmica costeira por obras pesadas no litoral, ou por acção do controle sobre caudais fluviais líquidos e sólidos, pode alterar em definitivo o NM local. Por outro lado, se o oceano aberto pode ser considerado um sistema linear, em águas baixas e junto à costa (como acontece junto ao marégrafo de Cascais), a topografia do fundo do mar, as correntes marítimas e, sobretudo, as correntes de maré introduzem perturbações que, nestas circunstâncias, tornam o sistema complexo (WELLS, 1997). Em tais circunstâncias, deve ainda considerar-se que, desde o final do século passado, a presença da nova marina de Cascais pode ter influenciado decisivamente os registos do marégrafo, já que a dinâmica litoral é certamente diferente.

Finalmente, uma referência a episódios periódicos ou mecanismos de grande período de retorno com influência no clima, que, por isso mesmo, não se devem reflectir numa variação centenária. Neste aspecto, apenas aqueles já referidos, como o ENSO, a NAO ou as manchas solares, deverão ser tidos em consideração de entre aqueles que estão representados no quadro da figura 3. Ainda assim, possivelmente por acção de fenómenos naturais paroxísmicos, segundo Ferreira (2002:10), nos últimos $80 \mathrm{mil}$ anos as sondagens oceânicas denunciam alterações bruscas do ritmo climático, que poderão assim ocorrer durante o período de existência da vida humana. Os mecanismos com periodicidades entre a dezena de anos e as dezenas de milhares que se conhecem mal (FERREIRA, 2002:10), são também passíveis de poderem influenciar valores de variações do NM anual (Fig. 3).

\begin{tabular}{|c|c|c|}
\hline PERIODICIDADE & MECANISMO OU FENOMENO & NATUREZA DO FENÓMENO \\
\hline 3 a 6 anos & ENSO & \multirow{2}{*}{$\begin{array}{c}\text { INTERACÇÕES } \\
\text { OCEANO-ATMOSFERA }\end{array}$} \\
\hline Cerca de 10 anos & NAO & \\
\hline 11 anos & MANCHAS SOLARES & ACTIVIDADE SOLAR \\
\hline $\begin{array}{l}\text { Dezenas a } \\
\text { centenas de anos }\end{array}$ & Mal conhecidos & Mal conhecido ou desconhecido \\
\hline 1 a 3 mil anos & $\begin{array}{l}\text { CICLOS } \\
\text { DANSGAARD-OERSCHER }\end{array}$ & \multirow{2}{*}{$\begin{array}{c}\text { INTERACÇÕES } \\
\text { CRIOSFERA-OCEANO- } \\
\text { ATMOSFERA }\end{array}$} \\
\hline 7 a 13 mil anos & EVENTOS DE HEINRICH & \\
\hline $21 \mathrm{mil}$ anos & PRECESSÃO EQUINOCIAL & \multirow{3}{*}{ VARIAÇÃO ORBITAL } \\
\hline $42 \mathrm{mil}$ anos & $\begin{array}{l}\text { OBLIQUIDADE DA } \\
\text { ECLIPTICA }\end{array}$ & \\
\hline 96 mil anos & $\begin{array}{l}\text { EXCENTRICIDADE DA } \\
\text { ORBITA TERRESTRE }\end{array}$ & \\
\hline
\end{tabular}

Fig. 3 - Periodicidades e mecanismos das variações climáticas (adap. de FERREIRA, 2002:11).

Fig. 3 - Periodicity and mechanisms of climate change (adap. from FERREIRA, 2002:11)

\subsection{Procedimentos estatísticos para realizar previsões e projecções}

As ferramentas estatísticas disponíveis em suporte lógico de uso comum, no caso estudado permitiram efectuar alguns exercícios de modo semi-automático, nomeadamente o ajustamento de linhas de tendência sobre a distribuição estatística e efectuar projecções para o futuro em função das suas equações. Todavia, é fundamental exercer sobre este procedimento uma análise crítica sistemática, sob pena de se efectuar uma análise desajustada da realidade, porque uma distribuição derivada de uma conjugação de fenómenos complexos, só dificilmente pode ser expressa por uma fórmula matemática que traduza essa complexidade. No entanto, há sempre a possibilidade de se poderem estabelecer algumas correlações significativas. Apesar de tudo, é frequente encontrar-se em trabalhos científicos sobre a matéria, análises de tendência baseadas em regressões lineares simples, induzindo em engano o observador mais desatento. Isto é tanto mais significativo e perigoso, quando tais reflexões são apresentadas a decisores políticos, cujo conhecimento de causa é em geral nebuloso. 


\section{Análise das Variações do Nível Médio ANUAL EM CASCAIS (1882-2005)}

\subsection{Análise da distribuição de valores inter- anuais do NM anual}

A figura 4, representa as variações inter-anuais do NM anual relativamente ao NM adoptado, verificadas com base nos registos do marégrafo de Cascais entre 1882 e 2005. Conforme referido anteriormente, estas devem reflectir a complexidade dos factores de variação. A simples observação do gráfico permite desde logo realçar dois aspectos: o primeiro é que, aparentemente, há uma tendência ascendente do NM. O segundo, que a amplitude máxima de variação em 123 anos foi de $25 \mathrm{~cm}^{8}$.

Foi em 1997 que o NM esteve mais elevado (18,6 cm acima do NM adoptado). Para que possa haver uma correcta interpretação do gráfico, há que salientar que o marégrafo sofreu uma recalibração por volta de 1950 , desconhecendo-se no entanto a sua data exacta. O facto é que parece ter tido uma influência decisiva nos valores absolutos posteriores. Este factor é aparentemente relevante, já que, como se irá verificar, até então o NM anual oscilava acima e abaixo do nível adoptado e, a partir de 1954, isso não mais voltou a acontecer, mantendo-se sempre bem acima do zero de referência. Esta rotura deve ser salientada porque é fracturante no que diz respeito à análise da tendência geral de variação considerando toda a série ${ }^{9}$.

Deste modo, a menos que se pudesse determinar um factor de ponderação para os valores posteriores a 1954, tem de se considerar este ponto de rotura e fazer análises separadas do período antes e depois daquela data. Por outro lado, verifica-se que o NM adoptado estará subdimensionado, já que a média dos valores do NM anual dos últimos 50 anos, está claramente acima do valor de referência, conforme foi calculado inicialmente e referido em 2.1. Estima-se então que o NM real deveria situar-se cerca de $10 \mathrm{~cm}$ acima do NM adoptado actual. Mas, tratando-se de facto de mudanças nas condições de registo, deixa assim de fazer sentido analisar a série como um todo.

Contudo, o conjunto completo de valores das variações do $\mathrm{NM}$ anual em torno do $\mathrm{NM}$ de referência, representados na figura 4 , mostram de facto a existência de uma clara alteração das condições de registo no período pós 1954; o qual surge logo a seguir a um triénio onde as diferenças inter-anuais foram muito elevadas.

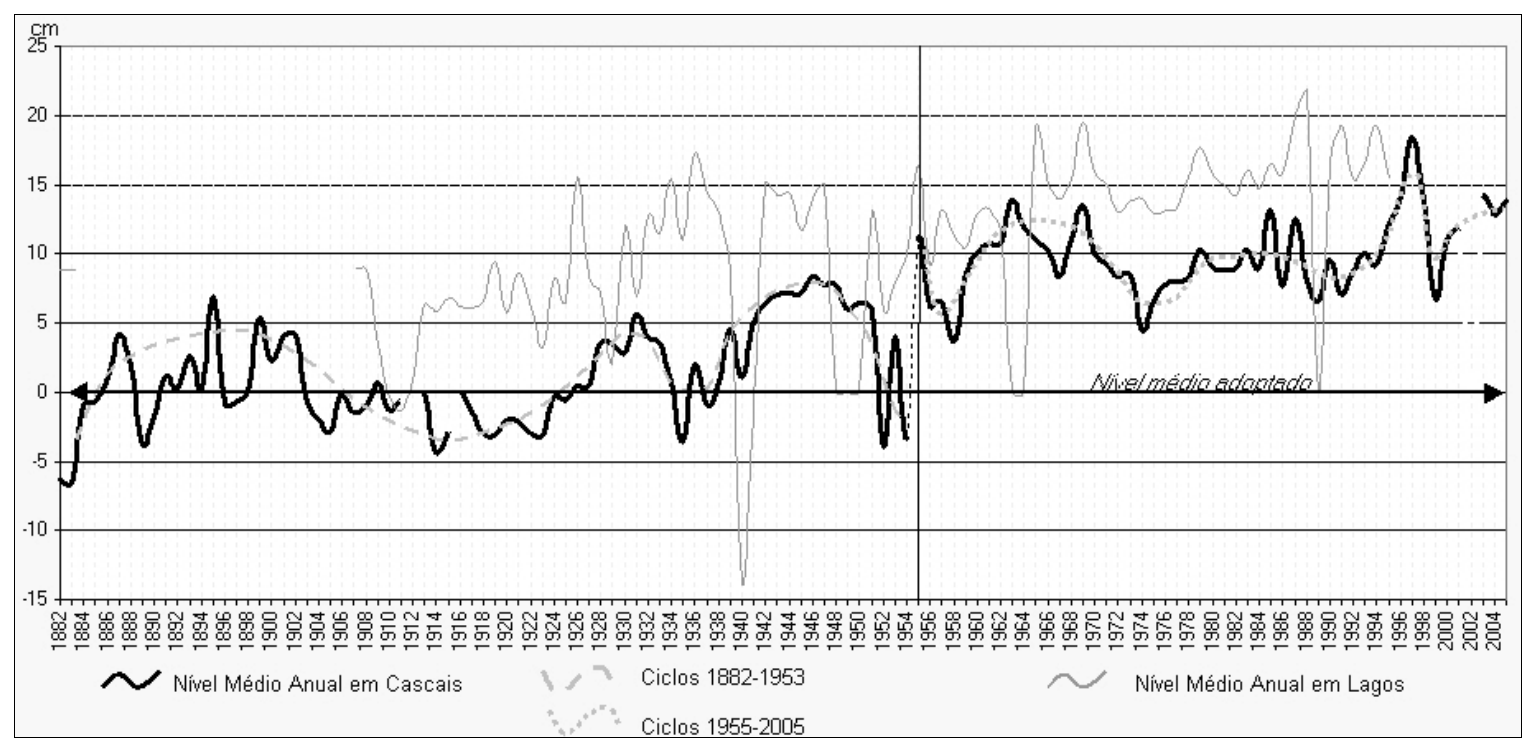

Fig. 4 - Variações inter-anuais do nível médio anual do mar em Cascais, entre 1882-2005, e em Lagos, entre 1908 e 1992, relativas ao nível médio adoptado. São representados ainda os grandes ciclos de variação do nível do mar em Cascais, anteriores e posteriores ao ano de 1954. Este gráfico foi elaborado a partir de dados cedidos pelo Departamento para a Geodesia, do Centro de Cartografia e Geodesia do IGP, 2007. Existem lacunas em Cascais nos anos de 1912-13, 1916 e 2002 e em Lagos nos anos de 1948-1950; 196364 e 1989.

Fig. 4 - Interannual variations of the annual mean sea level in Cascais, between 1882-2005, and in Lagos, between 1908 and 1992, related to the adopted mean sea level.

8 Soma dos valores extremos opostos: $(18,4 \mathrm{~cm}-[-6,6 \mathrm{~cm}])=25 \mathrm{~cm}$.

9 O valor do NM para toda a série é de $4,8 \mathrm{~cm}$ acima do actual nível de referência (ver Fig. 6). 
Não havendo registo concreto de fenómenos climáticos, oceanográficos, ou, principalmente, tectónicos com repercussões importantes a nível local que tenham ocorrido imediatamente antes deste período, tal anomalia não se justifica de outro modo que não seja por alteração acidental da cota do registo, aquando da referida recalibração deste, nos anos de 1950. Apesar de se terem feito diligências no sentido de apurar o que se terá passado, não foi possível determinar as causas de tal efeito. Por comparação, entre os registos de Cascais e de Lagos, verifica-se um desfasamento no ano de 1954, que sugere correspondência com a anomalia verificada. Não obstante o marégrafo de Lagos não ser uma referência fidedigna, pois foi deslocado e modificado ao longo da sua existência, os dados existentes têm vindo a ser utilizados e, como tal, tidos por válidos.

Assim, não sendo correcto analisar a distribuição como um contínuo, devem ser considerados dois períodos distintos, em que as oscilações do nível do mar são diferentes: o período anterior e o posterior a 1954 (Fig. 4), que em seguida são analisados separadamente.

\section{Período de 1882-1953}

Analisando a figura 4 e, se conseguirmos abstrair das irregularidades existentes no seu pormenor, visualizam-se três grandes ciclos $^{10}$ durante este período. No início da série, a partir de 1883, houve uma fase geral de subida do NM, mas irregular, com várias oscilações negativas de amplitude variável, culminando em 1895 com um máximo de $6,9 \mathrm{~cm}$ acima do nível de referência. No entanto, deve assinalar-se uma descida significativa em 1889, quando o NM baixou até um valor de $3,8 \mathrm{~cm}$. A partir de 1903, inicia-se uma fase de relativa estabilidade, com amplitudes inter-anuais fracas mas em fase descendente, cujo mínimo foi de $4,3 \mathrm{~cm}$ (1914) abaixo do nível de referência. Verificou-se, portanto, um contra ciclo, que durou mais de vinte anos.

Em 1924, começou um novo ciclo com uma fase inicial ascendente, lenta, mas quase sempre crescente, que culminou em 1931 (+5.6 cm), seguindo-se uma descida acentuada e contínua até 1935, em que se atingiu o mínimo $(-3,6 \mathrm{~cm})$. Durante os 11 anos seguintes o NM subiu e, se exceptuarmos as pequenas descidas de 1937 e 1940, houve um crescendo que culminou em 1946 $(+8,4 \mathrm{~cm})$. Seguiu-se uma nova fase descendente. Esta manifestou-se de forma ténue durante 5 anos, até que entre 1951 e 1952 houve uma queda brusca do NM, que desceu cerca de $10 \mathrm{~cm}$ de um ano para o outro. Poder-se-ia pôr a hipótese deste valor estar relacionado com as alterações no marégrafo ou falha de dados no cálculo do valor médio anual, mas esta descida significativa pode ser confirmada com o registo de Lagos (Fig. 4).

Por efeito, neste período, entre o final do século XIX e a primeira metade do século XX, generalizando, podem esboçar-se três ciclos de variação; o primeiro, cerca de 35 anos, é o mais longo, ultrapassando raramente o intervalo $[+5 \mathrm{~cm}$, $-5 \mathrm{~cm}]$. O ciclo seguinte é mais curto em termos temporais, durando apenas cerca de 20 anos. Por fim, o último ciclo corresponde a um período temporal de cerca de 16 anos, mas com a diferença de se iniciar e terminar de forma mais abrupta.

\section{Período de 1955-2005}

Pese embora não se conhecerem quaisquer referências a anomalias ou incorrecções respeitantes aos dados de 1953 e 1954, estes correspondem ambos a variações muito acentuadas e, pelo menos os de 1954, não nos parece ser fiáveis, dadas as circunstâncias já referidas, sobretudo por não serem confirmados pelos registos de Lagos. Neste último marégrafo, registou-se sempre uma ligeira subida em ambos os anos, o que poderá indiciar que a tendência de 1953 esteja correcta e o valor errado seja o de 1954. Não obstante, passa a considerar-se o início do novo ciclo em 1955, já com o nível de referência, provavelmente, num plano diferente da anterior. Durante estes cinquenta anos, os ciclos não são tão nítidos e, por isso mais difíceis de definir, havendo mais do que uma possibilidade de análise.

Apesar de uma descida entre 1955 e 1958, onde foi atingido um mínimo $(+3,7 \mathrm{~cm})$, a fase ascendente deste primeiro ciclo prolonga-se de forma irregular por cerca de dez anos e, ao fim de dezoito anos, o ciclo fecha-se em $1974(+4,4 \mathrm{~cm})$, após ter atingido entretanto dois máximos: em 1963 $(+13,9 \mathrm{~cm})$ e em 1969 (+13,5 cm). Entre 1974 e 1985, num período de 11 anos, o NM subiu até aos $13,1 \mathrm{~cm}$ (1985) e em 1987 ainda se registou um máximo secundário com $12,7 \mathrm{~cm}$. Nos dois anos seguintes, o NM baixa para atingir novo mínimo em $1989(+6,6 \mathrm{~cm})$, sendo no entanto importante referir que no período anterior (1882-1953) os máximos atingidos $(+6,6 \mathrm{~cm}$ e $8,4 \mathrm{~cm})$ estão sensivelmente ao nível deste mínimo.

De 1974 até 2005, os ciclos passaram a ser mais irregulares e mal definidos, embora em comparação com período anterior a 1954, com menores amplitudes de variação e períodos baixos mais breves. Em 1992 inicia-se um pequeno mas importante ciclo que tem uma fase ascendente abrupta e contínua (de 1995 a 1997), seguida de uma fase descendente, ainda mais acentuada, a qual termina em 1999.

10 Um ciclo corresponde a uma fase ascendente, seguida de uma descendente. Como a série começa numa fase baixa, passa a considerar-se um comprimento de onda, a distância-tempo entre duas cavas consecutivas. 
Até $2005^{11}$, há uma fase, aparentemente ascendente de um novo ciclo.

Não considerando a subida brusca de $14,3 \mathrm{~cm}$ entre 1954 e 55, o ano de 1995 marca, por conseguinte, o início da maior e mais rápida subida continuada do NM de toda a série, a qual culminou com o máximo absoluto de $1997(+18,4 \mathrm{~cm})$. Entretanto, em 1999, o NM já tinha caído para os $6,7 \mathrm{~cm}$. Neste particular, deve pôr-se a hipótese de uma possível relação inversa entre este episódio de abaixamento do nível do mar com a subida provocada no Pacífico pela ocorrência de um episódio muito forte do El-Niño entre 1997 e 1998 (NULL, 2004), funcionando a descida como uma espécie de compensação hidrostática. Inclusivamente, o próprio pico de 1997 pode já estar de algum modo relacionado com o fenómeno.
No entanto, a comparação directa é difícil, já que tanto o ENSO, como a La Niña (LNSO) ou a NAO, são fenómenos que ocorrem em poucos meses e atravessam em geral o ano solar. Logo o seu impacto é filtrado pelo facto do valor do NM anual ser precisamente obtido a partir de dados do ano solar. Já a explicação da grande subida entre 1994 e 1997 não é clara, embora seja admissível que possa estar de algum modo relacionada com o mesmo fenómeno. A complexidade e quantidade de fenómenos que podem desencadear alterações no NM, já foi mencionada e a busca por explicações carece de uma vasta e aprofundada investigação que não pôde ser efectuada para este trabalho. No entanto, a figura 5 mostra a posição dos valores anuais do NM em Cascais e a ocorrência dos três grandes fenómenos climáticos.

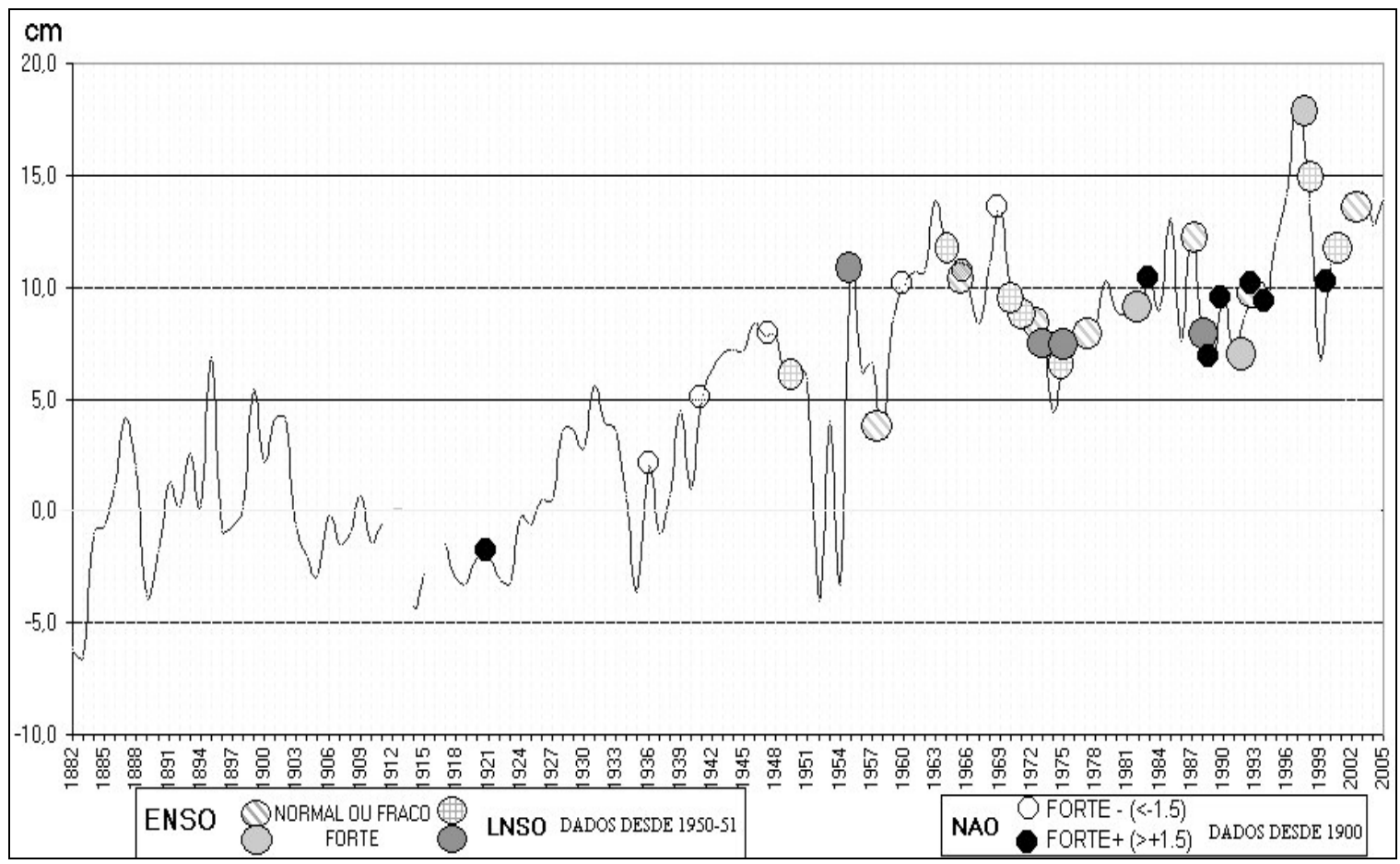

Fig. 5 - Relação entre nível do mar em Cascais e a ocorrência de fenómenos climáticos globais (ENSO, LNSO e NAO: dados obtidos a partir de Null, 2004).

Fig. 5 - Relations between mean sea level in Cascais and the occurrence of global climatic phenomena (ENSO, NAO and LNSO; data from Null, 2004).

Neste contexto não há, aparentemente, uma grande correlação entre os diferentes fenómenos cujas ocorrências estão representadas na figura 5 e a variação do NM em Cascais. Trigo et al. (2004), demonstra a existência de uma influência clara da NAO no clima Europeu e, sobretudo, na península Ibérica. É pois perfeitamente plausível que este modo climático exerça influência no NM anual. As interacções complexas e a duração relativa desses fenómenos faria esperar que não se pudesse estabelecer uma relação directa. Não obstante, alguns máximos e mínimos ocorreram nas proximidades de eventos importantes para além do já referido em relação a 1997 e 1999. Apenas os máximos de 1952, 1963, 1985 e 1986 surgem sem que tivesse havido alguma ocorrência próxima dos referidos fenómenos.

11 Na realidade, não se pode afirmar se esse ciclo é ou não ascendente embora o aparente. Para o confirmar, serão necessários os dados dos anos posteriores a 2005, ainda não disponíveis à data da realização deste artigo. 
Nos anos em que se verificaram, o pico de $1955(+)$ foi acompanhado por uma LNSO muito forte em 1955-56; o de 1958 (-) apanhou o El-Niño de 195758; o máximo de 1969 foi acompanhado de uma NAO (-); entre o máximo secundário de 1987 e o mínimo de 1989 houve um ENSO e uma forte LNSO; o mínimo de 1991 também pode ter sido influenciado pelo forte ENSO de 1991-1992 e, ainda, o ENSO de 2002-2003 pode ter afectado o valor máximo ocorrido em 2003 (NuLL, 2004). Apesar de tudo não é possível provar a existência de uma relação directa com aqueles fenómenos.

Por fim, desde 1999 que se está novamente a assistir a uma fase de subida ${ }^{12}$ que parece ter atingido o seu máximo em $2003(14,1 \mathrm{~cm})$, referindo-se ainda que 2005, foi um ano excepcional em termos climáticos por ter sido dos anos mais secos e quentes das últimas décadas. Tendo em conta a inércia global da resposta do oceano, o NM nos anos seguintes mais próximos poderá reflectir o efeito deste ano excepcional. Admite-se que, ainda assim, o menor afluxo de águas fluviais ao mar poderá já ter tido influência no valor anual, neste caso no sentido da sua diminuição. Não obstante, este ano apresenta o terceiro maior valor de toda a série após os de 1997 e 2003. De uma maneira geral, apesar de não ser possível estabelecer-se padrões de variação definidos, o carácter oscilatório e variável do NM anual em Cascais é evidente; não existe um nível do mar estável, não só entre anos consecutivos, como ao longo de períodos mais alargados. Há alternância irregular mas sistemática de fases de subida e de descida em que, considerando as duas partes distintas do registo (antes e depois de 1954), a sua variação média não ultrapassa os $5 \mathrm{~cm}$; ou seja, se o NM de referência estivesse de acordo com a média das oscilações poder-se-ia esperar que, em média, o NM anual pudesse estar $5 \mathrm{~cm}$ acima ou abaixo desse nível. Há, de certo, que introduzir nesta conclusão uma tendência que condiciona o valor do NM. Mas existindo uma marca de referência, seria possível fazer uma avaliação objectiva dessa tendência, não fora a anomalia verificada nos anos de 1950. A figura 6 dá uma ideia das características da distribuição de valores.

\begin{tabular}{|c|c|c|c|c|}
\hline PERIODO & $1882-2005$ & $1882-1935$ & $1955-2005$ & 1995-2005 \\
\hline $\begin{array}{l}\text { NM relatiwamente ao } \\
\text { NM adoptado: }\end{array}$ & $4.8 \mathrm{~cm}$ & $0.1 \mathrm{~cm}$ & $9.9 \mathrm{~cm}$ & $12.9 \mathrm{~cm}$ \\
\hline $\begin{array}{l}\text { Média das diferenças } \\
\text { entre anos } \\
\text { consecutivos }\end{array}$ & $1 \mathrm{~mm}$ & $3 \mathrm{~mm}$ & $3 \mathrm{~mm}$ & $-1 \mathrm{~mm}$ \\
\hline $\begin{array}{l}\text { Desvio padrão das } \\
\text { oscilaçấes do NM }\end{array}$ & $5.5 \mathrm{~cm}$ & $3.0 \mathrm{~cm}$ & $3.3 \mathrm{~cm}$ & $3.0 \mathrm{~cm}$ \\
\hline $\begin{array}{l}\text { Coeficiente de } \\
\text { variaçăo das } \\
\text { oscilaçôes do NM }\end{array}$ & $115 \%$ & $2157 \%$ & $31 \%$ & $23 \%$ \\
\hline $\begin{array}{l}\text { Oscilaçẫo máxima } \\
\text { positiva }\end{array}$ & $\begin{array}{l}18.4 \mathrm{~cm} \\
(1997)\end{array}$ & $\begin{array}{l}6.9 \mathrm{~cm} \\
(1895)\end{array}$ & $\begin{array}{l}18.4 \mathrm{~cm} \\
(1997)\end{array}$ & $\begin{array}{l}18.4 \mathrm{~cm} \\
(1997)\end{array}$ \\
\hline $\begin{array}{l}\text { Oscilação máxima } \\
\text { negativa }\end{array}$ & $\begin{array}{l}6.6 \mathrm{~cm} \\
(1883)\end{array}$ & $\begin{array}{l}6.6 \mathrm{~cm} \\
(1083)\end{array}$ & $\begin{array}{l}\text { näo houve } \\
\text { ascilações } \\
\text { negativas }\end{array}$ & $\begin{array}{l}\text { não hou'e } \\
\text { oscilaçốes } \\
\text { negativas }\end{array}$ \\
\hline $\begin{array}{l}\text { Maior diferença entre } \\
\text { anos consecutiros }\end{array}$ & $\begin{array}{c}14.3 \mathrm{~cm} \\
(1954-1955)\end{array}$ & $\begin{array}{c}7.8 \mathrm{~cm} \\
(1895-1896)\end{array}$ & $\begin{array}{c}7.2 \mathrm{~cm} \\
(1998-1999)\end{array}$ & $\begin{array}{c}7.2 \mathrm{~cm} \\
(1998-1999)\end{array}$ \\
\hline
\end{tabular}

Fig. 6 - Valores estatísticos relativos às variações do nível médio anual do mar em Cascais desde o início da série (1882) até 2005. Não foram contabilizados os valores relativos aos anos de 1912-13; 1916 e 2002. Verifica-se que, em média, nos primeiros cinquenta anos, o NM anual oscila em torno do NM adoptado, subindo aparentemente nos últimos cinquenta anos e, em especial, nos últimos dez. Mas, as amplitudes de variação inter-anual, mantêm-se quase idênticas ao longo da série, enquanto que, entre dois anos consecutivos, nunca terá havido mais de $7,8 \mathrm{~cm}$ de diferença.

Fig. 6 - Statistical values for changes in annual mean sea level in Cascais since the beginning of the series (1882) by 2005. Were not considered data for the years 1912-13, 1916 and 2002.

12 Não se considerou o ano de 2002 por falta de dados. 
A média global da série é de $4,8 \mathrm{~cm}$, o que significa que os valores registados, situam-se em média em torno dos $4.8 \mathrm{~cm}$ em relação ao NM de referência mas, conforme já foi referido, os valores relativos aos primeiros e últimos cinquenta anos não se podem comparar directamente em termos absolutos.

Nos primeiros, a série serviu para a determinação do NM de referência, razão pela qual o valor médio das oscilações é próximo do zero.

Nos últimos, muito provavelmente a partir de 1954, como houve a anomalia que fez com que o registo do NM ficasse muito acima do nível de referência, o valor médio de 9,9 cm (Fig. 6) não reflectirá qualquer subida do nível do mar, mas apenas uma provável mudança na cota original do marégrafo.

Já nos últimos dez anos, o valor médio de $12,9 \mathrm{~cm}$ atesta a fase ascendente do ciclo em que, na actualidade, nos encontramos, pois é um valor $3 \mathrm{~cm}$ acima da média 1955-2005. Este facto não pode constituir indício de que se esteja a verificar uma subida eustática do NM, mas apenas uma fase ascendente de um novo ciclo como houve tantas ao longo do período de medição.

$\mathrm{Na}$ tabela e no gráfico da figura 7 são representados os valores estatísticos das diferenças altimétricas do NM entre anos consecutivos, tendo como base variações absolutas. Deste modo, elimina-se a distorção que houve a partir de 1955.

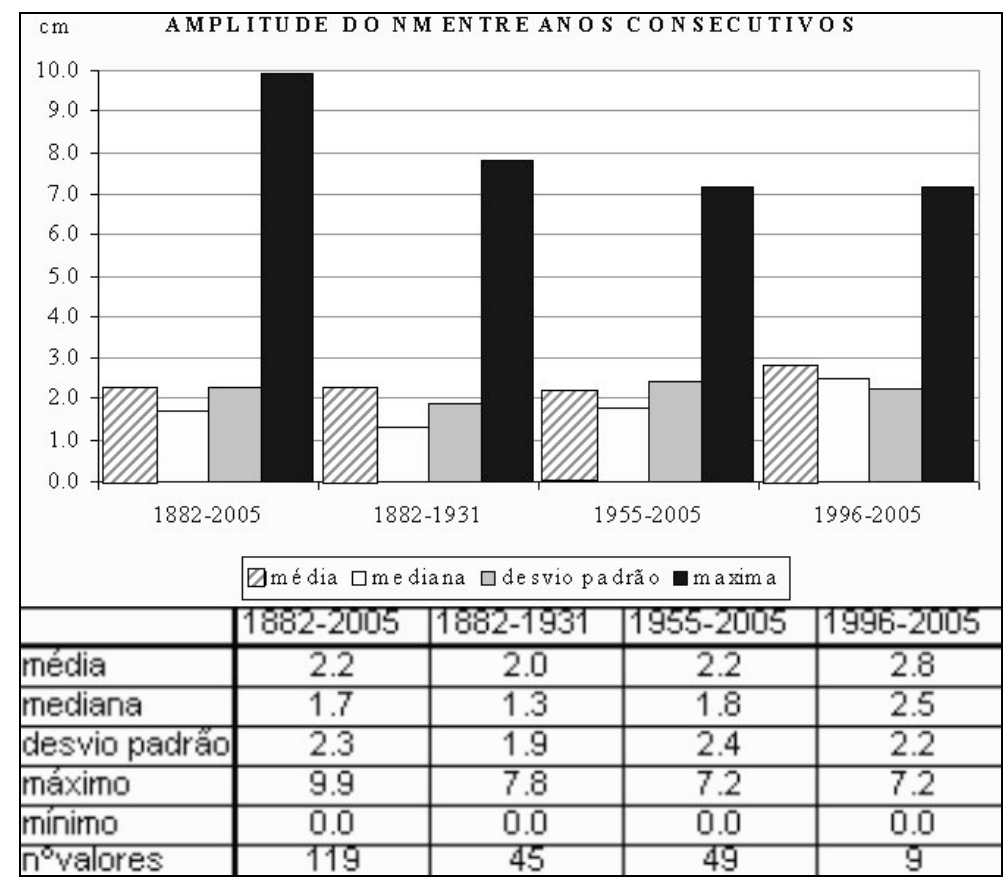

Fig. 7 - Valores estatísticos (em cm) das diferenças de amplitude do NM entre anos consecutivos. Fig. 7 - Statistical values (in cm) of the differences in amplitude of MSL between consecutive years.

Constata-se que, em geral, não existiram grandes variações do NM anual. Em média, varia $2,2 \mathrm{~cm}$ em cada ano, podendo subir ou descer $4,6 \mathrm{~cm}$, considerando o valor do desvio padrão. Neste sentido, variações superiores a este valor são raras e apenas uma vez se alcançou uma diferença máxima de $9,9 \mathrm{~cm}$ entre dois anos consecutivos (1951-1952) $)^{13}$; não se ultrapassando os $7,2 \mathrm{~cm}$ nos últimos cinquenta anos (1998-1999), sendo que corresponderam sempre a abaixamentos do NM. No meio século seguinte, a maior subida que se verificou foi apenas de $5 \mathrm{~cm}$. No total, em toda a série a diferença máxima registada foi de $8,0 \mathrm{~cm}$. Comparando as séries temporais referidas na figura 7, pode verificar-se que, em média, as diferenças de amplitude consecutivas aumentaram $2 \mathrm{~mm}$ nas últimas cinco décadas comparativamente à série 1882-1931, sendo mais significativas nos dez anos finais, onde essa média subiu $6 \mathrm{~mm}$.

A média da variabilidade inter-anual, representada pelo desvio-padrão, também aumentou nos últimos cinquenta anos em cerca de $5 \mathrm{~mm}$, mas diminuiu ligeiramente nos últimos dez.

13 A fiabilidade deste valor pode ser posta em causa, já que ocorreu na época em que houve mudanças no marégrafo. Mas, como já foi referido anteriormente, é considerado porque o valor de Lagos para o mesmo ano confirma a descida que se verificou em Cascais, ainda que naquele marégrafo essa tenha sido de menor amplitude (ver Fig.4). 
Em termos de probabilidades de ocorrência, foram efectuadas divisões em decis e quartis da série cronológica, cujos valores significativos são mostrados na figura 8.

Verifica-se que há apenas cerca de $10 \%$ de probabilidade de ocorrerem diferenças inter-anuais superiores a $5 \mathrm{~cm}$. É ainda de realçar o registo de valores consecutivos de baixa probabilidade de ocorrência, como nos anos de 1895 e 1896, 1951 e 1952, 1985 a 1988 e, finalmente, de 1997 a 2000. Terão sido estes os períodos onde o NM variou mais e de forma mais irregular.

Conclui-se que as variações inter-anuais do NM têm uma amplitude relativamente fraca, embora com uma certa irregularidade.

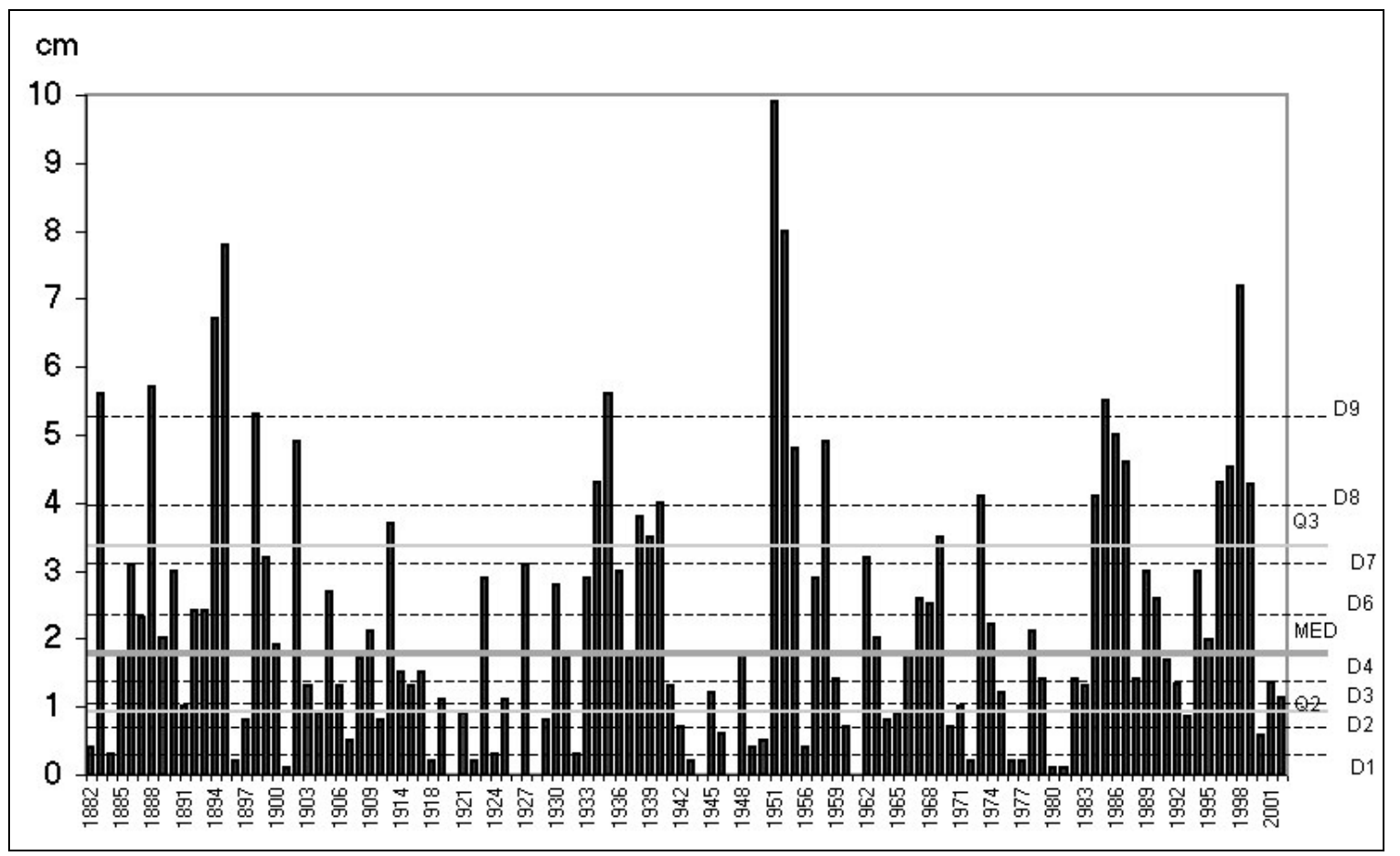

Fig. 8 - Probabilidades de ocorrências de diferenças inter-anuais entre valores absolutos do nível médio anual em relação ao nível de referência.

Fig. 8 - Probability of interannual differences between the absolute values of the annual mean sea level compared with the reference level.

\subsection{Tendências de variação e ajustamentos matemáticos}

A Climatologia não se encontra num estado evolutivo em que é capaz de fornecer intervalos de confiança, especialmente para o clima global num periodo futuro de 100 anos. Na realidade, mesmo o termo "incerteza" é enganador quando se trata de Climatologia. Uma série de coisas não são incertezas, mas são simplesmente desconhecidas!...(AGERUP, in IPN, 2004: 8-9, adap.). Esta afirmação produzida no âmbito do Relatório da Rede de Política Internacional sobre Impactos das Mudanças Climáticas (IPN, 2004), pode muito bem traduzir a realidade da qualidade das projecções que se fazem em torno do NM global. Por exemplo, Talke (1997), refere que recentes medições, indicam que o NM estará a subir $1 \mathrm{~mm}$ por ano ou $10 \mathrm{~cm}$ por século. Andrade e
Freitas (2002:183), com base numa tendência avaliada a partir de uma regressão linear sobre os registos de Cascais e Lagos (DIAS \& TABORDA, 1992), prevêem uma subida secular do NM de 1,3 $(+/-0.1)$ a $1,5(+/-0.2) \mathrm{mm} / \mathrm{ano}$, entre muitas outras projecções. De facto, parece pouco razoável efectuarem-se previsões, cujo impacto mediático é significativo, mas que são baseadas em dados ténues em termos de validade e, sobretudo, sem procurar salvaguardar a complexidade de factores intervenientes cuja maioria se podem incluir nas "incertezas" de que AGERUP se refere Os próprios autores desta previsão, já reconheceram posteriormente este aspecto. Para além disso, a existência de dados objectivos e quantitativos comparáveis que permitam a modelação desses factores, parece ser uma miragem, em especial, no que se refere aos mecanismos naturais de resposta do sistema oceano-atmosfera no sentido deste contrariar perturbações. Também a ligeireza com 
que as previsões são feitas e o modo como são apresentadas, não permite que a maioria possa ser levada a sério. Por exemplo, é enganador afirmar que em cem anos,

$$
\text { se o NM subiu } \mathbf{x} \text { então o NM sobe } \frac{x}{100} \text { por ano, }
$$

desprezando-se toda a complexidade de factores que em cem anos podem intervir no sentido de modificar qualquer tendência que se possa prever. Este tipo de lógica prospectiva, tende ainda a filtrar a variabilidade inter-anual que sempre se verifica. Outro exemplo que se pode dar e que reforça esta ideia, é o de que, se há 60 anos tivéssemos utilizado o mesmo registo maregráfico de Cascais para fazer previsões, é quase certo que não acertaríamos com a situação actual, até porque a tendência à época apontaria para uma ligeira descida do NM, o que não se veio a verificar.

Os registos do NM anual permitem, entretanto, ensaiar algumas abordagens estatísticas ao estudo de tendências, onde ficará demonstrado que o comportamento não linear dos factores intervenientes não permite que a estatística mais simples explique e entre em conta com essa complexidade (variabilidade e intensidade relativas) e possa gerar meios de previsão credíveis, que, por exemplo, possam conduzir à eventual tomada de medidas de prevenção ajustadas.

A análise de tendências assenta no propósito de que a distribuição de valores, representada pelo gráfico de valores das oscilações do NM em Cascais (Fig. 4), traduz a complexidade de factores que determinam os valores e a forma do gráfico do registo. Assim, de entre um grupo de soluções estatísticas disponíveis no suporte lógico utilizado procedeu-se ao ensaio e selecção da lei matemática que melhor se ajusta à distribuição de frequências. À partida, esse ajustamento deve ser verificado com a obtenção de um coeficiente de determinação $\left(\mathrm{R}^{2}\right)$ tão forte quanto possível.

Como não é possível determinar ao certo o valor da eventual correcção do nível de referência que seria necessário fazer na distribuição pós 1954, a análise é feita considerando uma rotura neste ano. No entanto, apesar de neste artigo se sustentar a tese de que, por volta dessa data houve uma anomalia desconhecida que condicionou o NM projectando-o no registo alguns centímetros acima do nível de referência original, apresenta-se um gráfico com as linhas de tendência sobre a série completa, porque é com base nesta que muitos autores fazem as suas previsões (Fig. 9). Não se consideram os valores em falta (1911-12, 1916 e 2002) bem como o valor polémico de 1954. Pelo que se deve salvaguardar as devidas reservas em relação às conclusões.

Dos tipos de regressão mais utilizados (linear, logarítmica e polinomial) seleccionaram-se duas. A linear, porque é a que mais se utiliza, embora seja a mais simplista, e a polinomial, neste caso a de grau 6 , que de todas foi a que forneceu valores de $\mathrm{R}^{2}$ mais elevados.

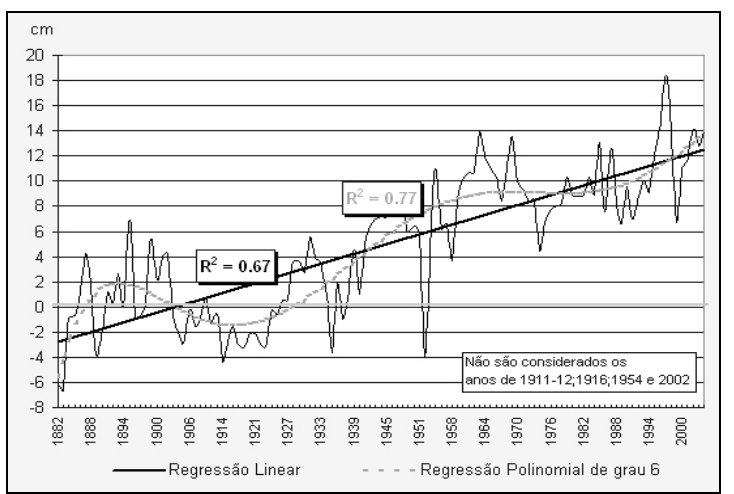

Fig. 9 - Tendências de variação do NM anual em Cascais entre 1882 e 2005.

Fig. 9 - Trends of variation of annual MSL in Cascais between 1882 and 2005.

Deste modo, para dar crédito ao gráfico da figura 9, como um todo, obtêm-se correlações fortes para a regressão linear $\left(\mathrm{R}^{2}=0.67\right)$ e sobretudo para a regressão polinomial de grau $6\left(\mathrm{R}^{2}=0.77\right)$. Ainda assim, a possibilidade de utilizar as leis matemáticas como base para previsão não é razoável uma vez que não há um ajustamento completo e essa tende a ser fortemente determinada pelos últimos anos, no caso da regressão polinomial.

Mas a abordagem mais correcta é a análise separada da série nas duas partes que a compõem. E neste particular o comportamento das linhas de tendência é claramente diferente (Fig. 10 e 11).

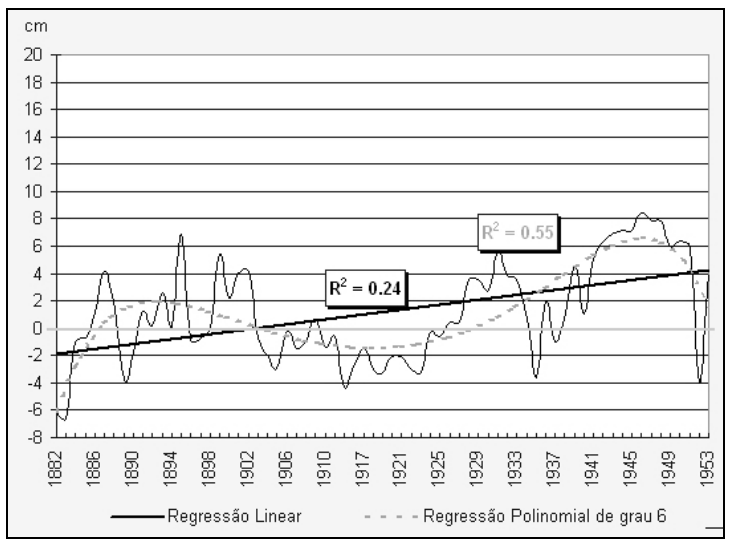

Fig. 10 - Linhas de Tendência do NM anual em Cascais, baseadas nos registos válidos entre 1882 e 1953.

Fig. 10 - Trend lines of the annual MSL in Cascais, based on valid records between 1882 and 1953. 
Ao contrário da análise de tendências baseada no registo completo (Fig. 9), tanto as tendências baseadas no registo das variações entre 1882 e 1953 (Fig. 10), como nas de 1955-2005 (Fig. 11) mostram, em geral, correlações muito fracas à excepção da regressão polinomial para 1882-1953, onde há uma correlação não muito forte e que reflecte uma nítida tendência para o abaixamento do NM.

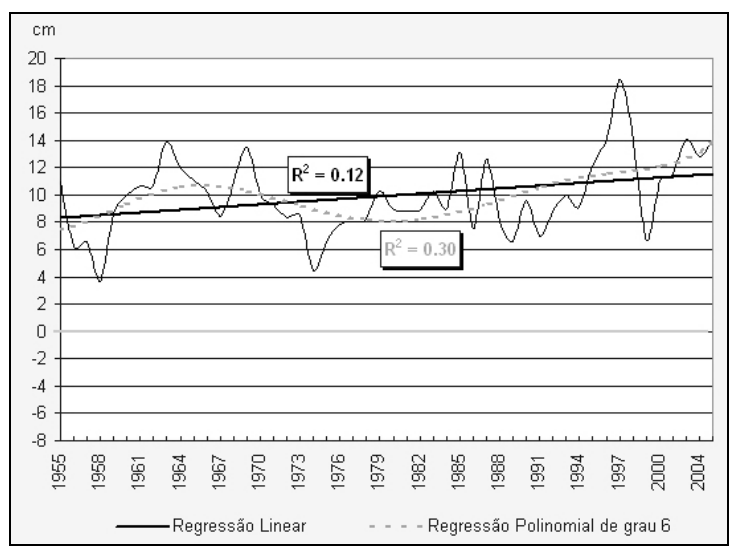

Fig. 11 - Linhas de Tendência do NM anual em Cascais, baseadas nos registos válidos entre 1955 e 2005.

Fig. 11 - Trend lines of the annual MSL in Cascais, based on valid records between 1995 and 2005.

Tanto na figura 10 como na 11 , do ponto de vista estatístico, a regressão linear não tem qualquer valor para assinalar uma previsão da tendência de variação, pois indica valores de $\mathrm{R}^{2}$ muito inferiores a 0.5 . Por comparação entre as duas figuras, pode observar-se facilmente o desajuste que separa os dois períodos. Na figura 10, o NM oscila em torno do nível de referência $(0,0)$ enquanto que na figura 11 , o registo está sempre bem acima desse nível. Esta condição regista-se subitamente a partir de 1955 e não se conseguiu obter uma explicação concreta para o facto. Portanto, à partida, esta metodologia não é adequada para se fazerem previsões baseadas no registo das oscilações do NM, neste período.

No entanto, apesar de não existir correlação entre a tendência desenhada pela regressão linear e a distribuição de frequências, o facto é que, ao efectuar-se um exercício de projecção deste tipo de linha de tendência para o futuro, obtêm-se hoje valores que, à partida, não seriam previsivelmente desajustados daquilo que se pudesse esperar.

A combinação de gráficos representada na figura 12 mostra o resultado desse exercício.

A regressão polinomial, apesar de melhor se correlacionar com a distribuição, não permite obter projecções aceitáveis, sendo fortemente condicionada pela tendência que ocorre nos últimos anos de cada série. Pelo contrário, a regressão linear, embora fracamente correlacionada com as distribuições, parece permitir a obtenção de projecções aceitáveis: na figura 12A, o NM estará em 2050 cerca de $13 \mathrm{~cm}$ acima do nível de referência e, no presente ano de 2007, estaria a cerca de $9 \mathrm{~cm}$. A diferença para o valor obtido em 2005 é de, aproximadamente, de $4 \mathrm{~cm}$ a menos, o que se enquadra dentro dos valores obtidos para o desvio padrão da série. Por seu lado, a projecção para 2050 baseada na série 1955-2005 (Fig.12 B), indica que o NM estará nesta data um pouco acima dos $14 \mathrm{~cm}$, que é o valor que, por exemplo, foi atingido em 2005. Utilizando a recta da figura $12 \mathrm{C}$, então o NM estará um pouco acima dos $18 \mathrm{~cm}$.

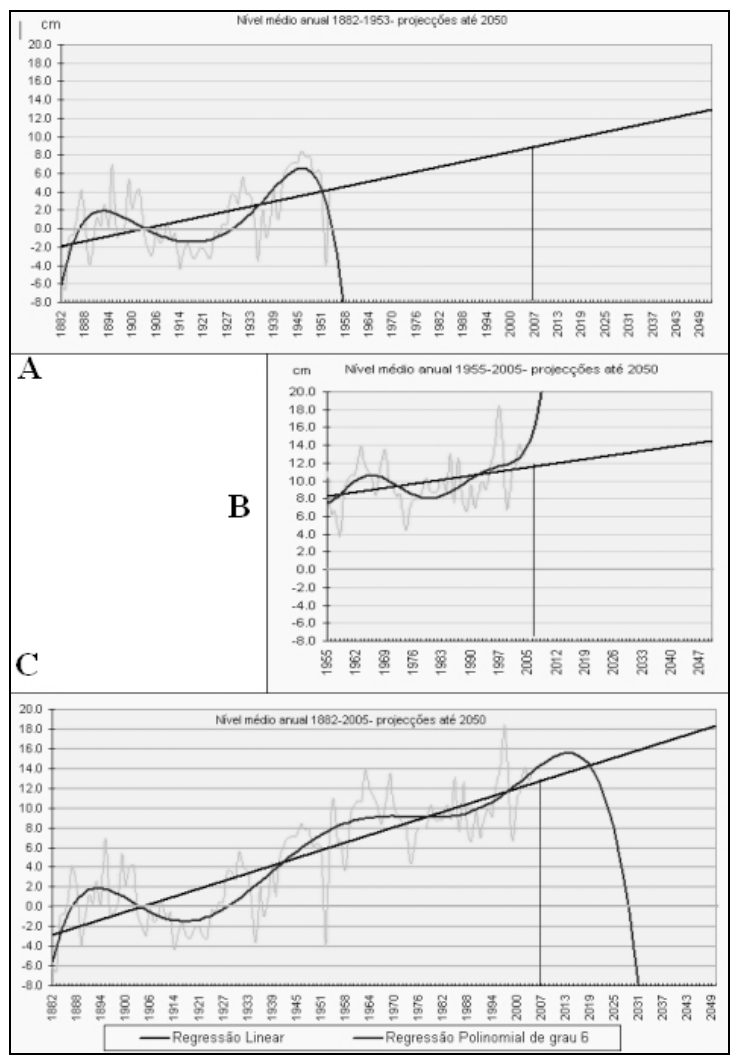

Fig. 12 - Projecções do NM para 2050, baseadas nas linhas de tendência calculadas a partir de regressão polinomial e linear.

A - Projecções baseadas na série 1882-1953;

B - Projecções baseadas na série 1953-2005;

C - Projecções baseadas na série 1882-2005.

Fig. 12 - MSL's projections for 2050, based on trend lines calculated from polynomial and linear regression.

A - Projections based on 1882-1953 series;

B - Projections based on 1953-2005 series;

C - Projections based on 1882-2005 series.

Mas estas previsões sofrem de 2 vícios importantes que à partida as invalidam. O primeiro, é o de que se está a aferir ou a conferir uma 
previsão com base em valores que estão sobrelevados artificialmente desde 1954, o segundo que se está a usar uma lei matemática que não tem correlação com a distribuição. O caso da figura $12 \mathrm{C}$ é meramente exemplificativo, já que não é lícito traçar uma projecção sobre todo o registo, mas a única que à partida se pode validar é aquela que se baseia na regressão de 1882-1953. No entanto, os valores não são comparáveis com os da série 19552005. Se assim fosse, a previsão estaria mais ou menos correcta mas, atendendo à provável descalibração do NM em Cascais desde 1954, a previsão, à partida, será inválida já que o NM estará, em valor absoluto, abaixo dos valores indicados pelo registo.

Uma aproximação possível, para se saber se os actuais valores indicados por Cascais estão correctos é compará-los com os valores de outros marégrafos. Mas, conforme a figura 2, não há séries suficientemente longas para o efeito. No entanto, pode fazer-se o exercício de comparação com Lagos, embora aqui só se disponha de valores até 1992. Os anos seguintes só poderão ser comparados a partir de 1997 com os dados recolhidos no marégrafo de Sines.

Por exemplo, de acordo com a figura 4, há um certo paralelismo entre as variações de Cascais e Lagos, mas os registos dos valores do NM em Lagos, salvo em quatro excepções, estão sempre a mais de $5 \mathrm{~cm}$ acima do NM de referência. É certo que há também uma tendência de subida, mais acentuada que em Cascais, mas também há maiores amplitudes de variação inter-anual, logo não é possível confirmar se os valores actuais de Cascais estão ou não próximos da realidade. Ainda em relação a Lagos, existem anos em que houve oscilações em sentido oposto; isto é, enquanto que em Cascais o NM anual subia, em Lagos descia ou vice-versa, como ocorreu em $37 \%$ dos anos comuns. Apesar disso, há uma correlação de 0.63 entre os registos dos dois marégrafos. Em relação a tendências, a fazer fé na regressão linear e na validade dos valores em ambos os casos, há uma tendência quase paralela para uma SNM ligeiramente mais acentuada em Lagos.

No que diz respeito a Sines e aos valores do período de 1997 a 2005, verificou-se que, aqui, o NM está muito acima do de referência, oscilando entre 10 a $20 \mathrm{~cm}$ acima (o valor médio é de $15,2 \mathrm{~cm})$. A correlação com Cascais é média $(\mathrm{R}=0.5)$ e inferior à de Lagos pese embora se trate de períodos diferentes, mas a tendência de variação é inversa. Apenas com base nesta curta série, o NM tende a subir em Sines, enquanto que em Cascais tende a descer (Fig. 13). Mais uma vez, a correlação da regressão linear que indica esta tendência é muito baixa.

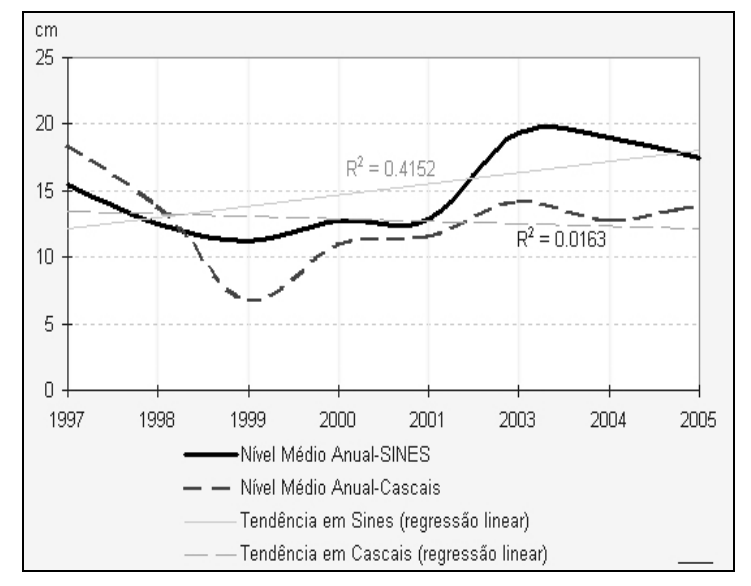

Fig. 13 - Nível médio anual em Sines e relação com Cascais, 1997-2005, sem 2002 (fonte: IH, 2006).

Fig. 13 - Annual mean sea level in Sines and its relationship with Cascais, 1997-2005, without 2002 (source: IH, 2006).

\section{Conclusões}

As conclusões retiradas centram-se no marégrafo de Cascais e, como tal, não devem ser extrapoladas para outros locais. A principal é a de que não é lícito estabelecer-se uma previsão da variação do NM ao longo dos anos, baseada na totalidade da série de dados disponível.

Numa perspectiva de escala de tempo abrangente, enquadrada num período interglaciar que começou há cerca de 18000 anos, que teve diversas oscilações, mas que impôs uma tendência global de subida ao NM, pode considerar-se que o período a que diz respeito à série de dados a partir da qual se determinou o NM de referência, não corresponde necessariamente a um período particular de estabilidade ou normalidade eustática do NM. Tanto mais que em relação a dados de marégrafos não há referências anteriores pois o de Cascais é dos mais antigos do mundo. Tal não significa que não existam outros meios de determinar a posição relativa do nível do mar. Existem, nomeadamente os geomorfológicos e os paleoclimáticos, mas aqui fala-se de dados de observação directa, medidos e registados e os apresentados foram os dados possíveis de obter. Apesar de tudo têm servido para estereotipar um padrão de "normalidade", que não se sabe bem o que será e que poderá até corresponder, ou não, a uma fase em que o NM esteve baixo. Se assim é parece lógico que a partir de 1938 o NM pudesse ter subido naturalmente. É óbvio que até 1938, o NM teria de oscilar acima e abaixo do nível de 
referência, já que este foi obtido com base na média 1882-1938. Portanto, a representatividade da série 1882-1938 é questionável como padrão de normalidade da posição do NM. Mas o facto é que não há outra alternativa, senão a de usarmos esse ponto de partida. Por isso dizemos que, hoje, o NM de referência parece aparentemente subdimensionado para as condições actuais, mas qual será o período mínimo para se fazer um NM de referência mais de acordo com a realidade? E essa realidade, dinâmica, não se vai também alterando?

Nos dados a que se teve acesso (Lagos, Sines e Cascais) os valores do NM estão, sistematicamente, uns centímetros acima do zero de referência estabelecido em 1938 a partir da série de Cascais; mas, nesta houve um problema, identificado à partida no período entre 1954 e 1955, a partir da qual o NM que até então oscilava acima e abaixo do nível de referência passou a estar sempre bem acima desse nível, parecendo, claramente, uma SNM forçada. Deste modo, efectuou-se uma análise separada das séries anteriores e posteriores àquele período, que foi inconclusiva em termos de poder fornecer previsões seguras. Isto deve-se ao facto dos actuais registos do NM em Cascais poderem, ou não, estar sobrelevados dado que após 1954, pode ter havido um reajustamento, não documentado e não visível no gráfico que, de algum modo, pudesse ter permitido determinar o momento a partir do qual os valores registados se poderiam ter aproximado dos valores reais. Os valores de Sines e Lagos permitem colocar essa hipótese. Admitindo a sua validade, ainda assim haveria dois aspectos a reter. O primeiro é de que não há nenhum indício de uma subida acentuada no NM. No máximo, em 2050 o NM estaria a pouco mais de $18 \mathrm{~cm}$ do nível de referência de 1938, portanto já próximo do actual. O IPCC (2001) aponta para 2050 um NM entre 10 a $22 \mathrm{~cm}$ acima do NM de 1990. Observando o dramatismo que se faz em redor da eventual subida global do NM, poderá ter existido um certo exagero nas afirmações proferidas, até porque em anos onde se conjugam as situações mais extremas em termos climáticos e oceanográficos (baixas pressões, vento, ondulação forte e marés muito elevadas) o nível do mar pode subir mais de $1 \mathrm{~m}$ no período de algumas horas. Em 1997, o NM anual ultrapassou mesmo o valor indicado para 2050. Todavia, pode-se concluir em definitivo, independentemente do NM estar mal ou bem aferido, que pelo menos em Cascais, não há uma subida constante, nem crescente, do NM. Mostrou-se que há ciclos com fases (de subidas ou descidas), que podem durar vários anos e, como refere Dias (2001), são necessárias algumas décadas para poder estabelecer se há ou não uma subida ou descida do NM e, ainda, acrescentando, se não houver alterações das condições de medição iniciais.
Salvo em raras excepções, não foi também possível estabelecer um paralelismo ou uma relação de causa efeito directa entre anomalias climáticas globais e variações do NM. Talvez o caso de 19971998 esteja ligado ao ENSO, mas, afirmá-lo de forma definitiva, é prematuro, pois não há uma clara relação e, a existir, será difícil de provar. A complexidade e quantidade de factores que podem fazer subir ou descer o NM e o modo como se reflectem num registo do NM anual é algo que ainda transcende a Ciência. São o que Dias (in TAVARES et al., 2004) chama de múltiplos forçamentos a que está sujeito o litoral. Apenas as marés e a ondulação são, à partida, os únicos fenómenos detectáveis e quantificáveis e isso não basta para se fazerem previsões alarmistas capazes de criar angústia a quem se preocupa ou vive com o mar e na sociedade em geral. Não obstante, todos os anos o NM continuará a variar, uns anos numa posição mais elevada e outros mais baixa. Não há, na álgebra linear, fórmulas que expliquem $o$ fenómeno e que, a partir daí, permitam fazer projecções seguras. Estaremos ainda no domínio das hipóteses que não se podem testar experimentalmente (DIAS, 2004).

O que existe é uma possibilidade real de que os efeitos da acção antrópica sobre o clima e os oceanos possa produzir uma SNM que, em Cascais é, pelo menos, pouco clara e, no máximo, será pouco significativa.

\section{Agradecimentos}

Ao Prof. Doutor Rui Reis (IGP) e ao $\mathrm{Eng}^{\mathrm{o}}$ António Jorge Silva pelas sugestões efectuadas e conselhos dados ao nível de problemas matemáticos. À Dra. Alexandra Morgado (IH), pela ajuda na obtenção dos dados de Sines. Aos estagiários do Departamento de Geodesia do IGP, Eng $^{\text {os }}$. Nuno Afonso, Carlos Colaço e Vasco Lopes que compilaram os dados maregráficos de 2001 a 2005 .

\section{BIBLIOGRAFIA}

ANDRADE, C.F. \& Freitas. M. (2002). Coastal Zone, in F.D. Santos et al. (eds.) Cap. 6, Projecto SIAM, Gradiva, Lisboa, pp. 175-215.

Bell, C.; VAssie, J.M. \& WoOdWorth, P.L. (2000). TaskTidal Analysis Software Kit, Permanent Service for Mean Sea Level, CCMS Proudman Oceanographic Laboratory, Bidston Observatory, Merseyside, U.K.

CABral, J.M. (1993). Neotectónica de Portugal Continental. Dissertação de Doutoramento, Universidade de Lisboa, Lisboa.

ChAmBers, D. (2006). Observing seasonal steric sea level variations with GRACE and satellite altimetry, Journal of Geophysical Research, Vol. 111 (C3), Notes 111, Note(s): C03010.1-C03010.13. 
DiAs, J.A. (2001). A Elevação do Nível do Mar, Art. base publicado na Revista Ambiente e Magazine.

DIAS, J.A. (2004). História da Evolução do Litoral Português nos Últimos Vinte Milénios, in A. Tavares et al. (eds.), Evolução Geohistórica do Litoral Português e Fenómenos Correlativos, Universidade Aberta, Lisboa, pp. 157-170.

DiAS, J.A. \& TABORDA, R.M. (1992). Tide-Gauge Data in Deducing Sea Level and Crustal Movements in Portugal, Journal of Coastal Research, 8 (3) pp. 655-659.

FERrEIRA, A.B. (2002). Variabilidade Climática e Dinâmica Geomorfológica, Contribuições para a Dinâmica Geomorfológica, APGEOM, Vol. I, Lisboa, pp. 7-15.

IGP - InSTITUTO GEOGRÁfICO PORTUGUÊS (2007). Valores das variações do nível do mar em Cascais (1882-2005), Departamento de Geodesia, Lisboa (não publicado).

IH - Instituto Hidrográfico (2006). Dados de Marés do Ano de 2005 - Sines - Posto 3- (Thales), Relatório Técnico, Ministério da Defesa Nacional, Marinha, Lisboa.

IPCC - InTERgovernmental PANEL For Climate Change, (2001). Climate Change 2001: The Scientific Basis, ONU, Nova Iorque, http://www.ipcc.ch/ipccreports/tar/wg1/index.htm

IPN - INTERNATIONAL POLICY NETWORK (2004). The Impacts of Climate Change: An appraisal for the future, International Policy Press, Londres.

MÖRNER, N-A. (2005a). Sea Level changes and crustal movements with special aspects on the Eastern Mediterranean, Zeitschrift für Geomorphologie, sup. Vol. 137, pp. 91-102.
MÖRNER, N-A. (2005b). Facts and Fiction about Sea Level Changes, apresentação na The House of Lords Economic Affairs Commitee, Londres.

NULL, J. (2004). El Niño \& La Niña Years: a consensus list, Golden Gate Weather Services, http://ggweather.com/enso/years.htm

PASKOFF, R. (1985). Les Littoraux: Impact des aménagements sur leur evolution, Masson, Paris.

TALKE, E. S. (1997). Sea-level rise,

http://www.iitap.iastate.edu/gcp/sealevel/sealevel_lecture.html

TAVArES, A.A.; TAVARES, M.J.\& CARDOSO, J.L. (Eds.) (2004). Evolução Geohistórica do Litoral Português e Fenómenos Correlativos. Actas do $1{ }^{\circ}$ Simpósio, Universidade Aberta, Lisboa.

Trigo, R.; POZO-VÁzQuez, D.; OsBorn, T.J.; CASTRO-DÍEZ, Y.; GÁMIZ-ForTIS, S. \& EsTEBAN-PARRA, M.J. (2004). North Atlantic Oscillation Influence on Precipitation, River Flow and Water Resources in The Iberian Peninsula, International Journal of Climatology, 24, pp. 925-944.

UNESCO (1985). Manual on Sea Level Mesurement and Interpretation - Vol. 1, Intergovernmental Oceanographic Commission, Mersayside, UK.

Wells, N. (1997). The Atmosphere and Ocean: A Pshysical Introduction, $2^{\mathrm{a}}$ ed., Wiley, Chichester. 